R.E. ŚLIWA**, T. BALAWENDER*, E. HADASIK**, D. KUC**, A. GONTARZ***,

A. KORBEL****, W. BOCHNIAK****

\title{
METAL FORMING OF LIGHTWEIGHT MAGNESIUM ALLOYS FOR AVIATION APPLICATIONS
}

The work presents an analysis of selected magnesium alloys as structural materials to be used in production of aircraft parts as well as their technological parameters in some manufacturing processes. Upsetting test, backward extrusion and Kobo extrusion of complex cross-sectional profiles and forging process were realized using magnesium alloys AZ31, AZ61, AZ80, WE 43 and Mg alloy with Li for production of thin - walled aircraft profiles and forged aviation parts. The range of temperatures and extrusion rate for the manufacturing these profiles were determined. Tests also covered the analysis of microstructure of $\mathrm{Mg}$ alloys in the initial state as well as after the extrusion process. It has been proved that the proper choice of parameters in the case of a specific profile extruded from magnesium alloys allows the manufacturing of products of complex cross-sections and the quality required in aerospace industry. This has been demonstrated on the examples of complex cross-sectional profiles using elements of varied wall thickness and examples of forged aviation parts: aircraft wheel hub and helicopter lever for control system.

Keywords: upsetting, forging, backward extrusion, KOBO extrusion

\section{Introduction}

Magnesium alloys possess many excellent mechanical properties, so they are widely employed in such industry areas as vehicle, aviation, spaceflight, electronic communication and others. They are characterized by light weight, high specific strength and shock resistance, strong thermo-conductivity and electromagnetic shielding. These alloys are easy to recycle and can be regarded as "the green material" with the greatest application potential in the 21 st century [1].

The plasticity of magnesium alloys is limited at room temperatures because of the hexagonal close-packed (HCP) crystal structure, in which only a few slip systems are available to move, so the plastic working of these alloys can be done at elevated temperatures $[2,3]$. This is a basic disadvantage of magnesium and its alloys. Temperatures above $200^{\circ} \mathrm{C}$ permit the activation of other slip systems as well as the formation of twin's deformation enabling these materials to be hot workable. The temperature range between the brittle and the plastic deformation behaviour of magnesium alloys is narrow, e.g. magnesium alloy AZ61 has a limited workability at $208^{\circ} \mathrm{C}$ and high ductility at $220^{\circ} \mathrm{C}$, what means that increase of only $12^{\circ} \mathrm{C}$ involves significantly better deformation properties [4]. During the hot deformation, some metallurgical phenomena such as work hardening, dynamic recovery and dynamic recrystallization occur simultaneously, resulting in material structure and physical properties. Studies on AZ31 alloy showed that the deformation which occurred by twinning in low temperatures, was gradually replaced by dynamic recrystallization in temperature above $300^{\circ} \mathrm{C}$, reduction in flow stress and increase in ductility. These phenomena were observed due to increased dynamic recrystallization above $360^{\circ} \mathrm{C}$ [5]. Transformation of the coarse cast structure into a fine grain elongated structure, which occurs during hot working in the extrusion process, significantly improves the mechanical properties of the magnesium alloys. Magnesium alloys have low volume heat capacity. The velocities of heating and cooling are therefore much quicker than those of other metals. Additionally, magnesium and its alloys have a narrow range of heat working temperatures. The above causes many difficulties to the processing of magnesium alloys and restricts the development of manufacturing industry as well as the application of magnesium products.

A very popular group of magnesium alloys are those containing aluminium with addition of zinc and manganese. Such materials, due to the used ingredients, are relatively cheap. They are characterised by beneficial set of mechanical properties. The most popular is AZ31 alloy which is characterised by good deformability and is processed in conditions of rolling, extrusion or forging. Strength of the alloys from this group increases with the increase of aluminium content. For elements which are supposed

\footnotetext{
* RZESZOW UNIVERSITY OF TECHNOLOGY, 8 POWSTAŃCÓW WARSZAWY STR., 35-959 RZESZÓW

** SILESIAN UNIVERSITY OF TECHNOLOGY, 2A AKADEMICKA STR., 44-100 GLIWICE, POLAND

*** LUBLIN UNIVERSITY OF TECHNOLOGY, 38D NADBYSTRZYCKA STR., 20-001 LUBLIN. POLAND

**** AGH UNIVERSITY OF SCIENCE AND TECHNOLOGY, AL. A. MICKIEWICZA 30, 30-059 KRAKÓW, POLAND

\# Corresponding author: rsliwa@prz.edu.pl
} 
to have bigger strength it is better to use alloys marked as AZ61 and AZ80 which include respectively 6 and $8 \%$ of aluminium. Alloy AZ31 may reach ultimate tensile strength of $260 \mathrm{MPa}$, alloys AZ61 and AZ80 respectively 325 and $350 \mathrm{MPa}$ after extrusion. Together with increase of aluminium content the plasticity and susceptibility to plastic treatment in lower temperatures decreases [5]. Alloy WE43 belongs to the group of magnesium alloys which includes rare earth elements, mainly $\mathrm{Y}, \mathrm{Re}$ and $\mathrm{Zr}$. This alloy is used as casting alloy and it is also shaped with the use of plastic processing. Alloy type WE43 has beneficial resistance properties and can be applied up to temperature of $300^{\circ} \mathrm{C}$ [6]. It is also characterised with better resistance to corrosion in comparison to classic alloys of magnesium with aluminium. Due to those factors it can be applied on such construction elements in aviation which are prepared with the use of forging or extrusion. These materials are often used as foundry materials.

Nowadays, magnesium products are commonly manufactured by casting processes. But the mechanical properties of casted products are not sufficient for the use in many applications. Plastic working obviously improves the mechanical properties of magnesium parts compared with casting ones, but the poor ductility at room temperatures causes that plastic working of magnesium alloys should be done at elevated temperatures. The minimum billet temperature is the result of material properties and machine capacity and it should lead to the achievement of adequate formability of an alloy and sufficient quality of a product.

The main manufacturing methods of magnesium alloy products are press forming, forging, rolling and extrusion. During extrusion, high mean compressive stresses in the deformation zone enable processing materials with limited workability. The extrusion is used mainly for the production of different kinds of sections in aluminium alloys and copper alloys industry. Other metal sections and semi-finished products are also produced in small quantities by extrusion. The extrusion processes for magnesium are performed like for aluminium alloys but the extrusion speed is much lower than for aluminium alloys [6-9]. The ratio of the billet cross-sectional area $A_{o}$ to that of the extruded section $\mathrm{A}$ is the extrusion ratio $\lambda=\mathrm{A}_{\mathrm{o}} / \mathrm{A}$. High values of the extrusion ratio require a low flow stress of extruded material and a high pressure of a press. So, extrusion is usually carried out at high temperatures.

Magnesium alloys are mainly extruded using a forward extrusion process, but a backward extrusion is possible and is used [4]. The working temperatures for extrusion magnesium alloys are at 250 to $450^{\circ} \mathrm{C}$, depending on the alloy and are higher than those used for hot rolling the same magnesium alloys. The extrudable magnesium alloys belong to the category of difficult-to-extrude alloys; the extrudability of magnesium alloys decreases with increasing aluminium content as do the extrusion speeds. The extrusion speeds fall in the range of moderate-todifficult-to-extrude aluminium alloys [4].

To determine proper parameters of extrusion process it is necessary to know exact information on initial features of given magnesium alloy - its macro and microstructure, mechanical properties and final results of transformation of the internal structure under conditions of plastic deformation e.g. in the extrusion process.

The objective of the present study was to investigate the potentials of the backward extrusion, forging and KOBO extrusion processes of magnesium alloys to apply them as materials for aeronautical applications. The final goal is to indicate best materials and parameters of the process to use e.g. bridge dies to produce tubes and different types of hollow sections or complex profiles which are the interest of aviation industry in light extruded products in order to save energy, costs etc. by reducing aircraft weight.

\section{Experimental work}

\subsection{Materials and upsetting test}

In order to prepare technology of plastic processing it is necessary to define precisely the plastic properties and microstructure changes of those alloys. The aim of the paper was to compare the plasticity and microstructure of magnesium alloys with from 3 to $8 \%$ aluminium content from group $\mathrm{Mg}-\mathrm{Al}-\mathrm{Zn}-\mathrm{Mn}$. On the basis of tensile tests, the plasticity changes were determined in temperature from 150 to $450^{\circ} \mathrm{C}$. Conducted compression test at temperature from 250 to $450^{\circ} \mathrm{C}$ and deformation speed from 0.01 to $10 \mathrm{~s}^{-1}$ provided important data concerning the influence of process parameters on flow stress and microstructure changes connected with recrystallization process.

To evaluate mechanical behaviour of the material in extrusion process the upsetting test was used to realized plastic deformation in various conditions and to look for adequate their choice for real deformation process. Different types of magnesium alloys were used in the study, i.e. grades AZ31, AZ61, AZ80, WE43 and magnesium alloys with lithium, as casted ingots and extruded preforms. In order to study feasibility of these magnesium alloys in extrusion process, the upsetting process of cylindrical specimens was carried out. The dimensions of cylindrical specimens were equal: diameter $\phi 20 \mathrm{~mm}$ and height $25 \mathrm{~mm}$. Before upsetting specimens were heated in a furnace to established temperatures.
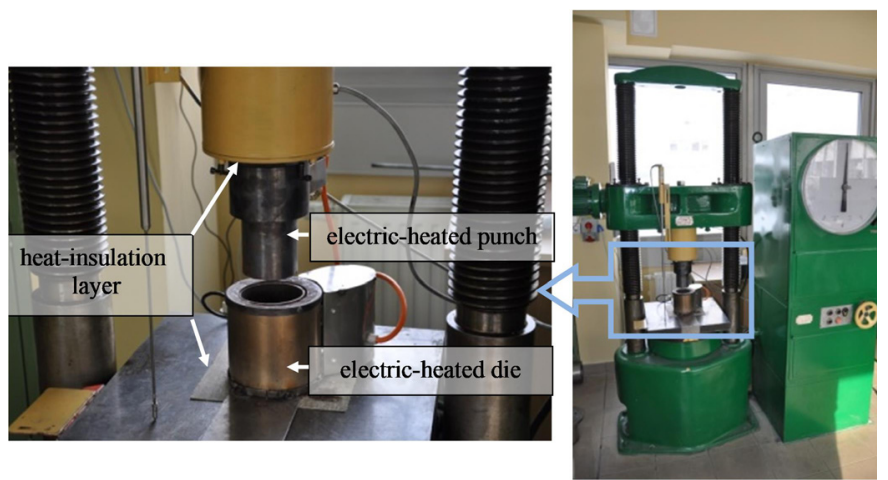

Fig. 1. Set-up of the upsetting test in high temperatures mounted on $1000 \mathrm{kN}$ hydraulic press 

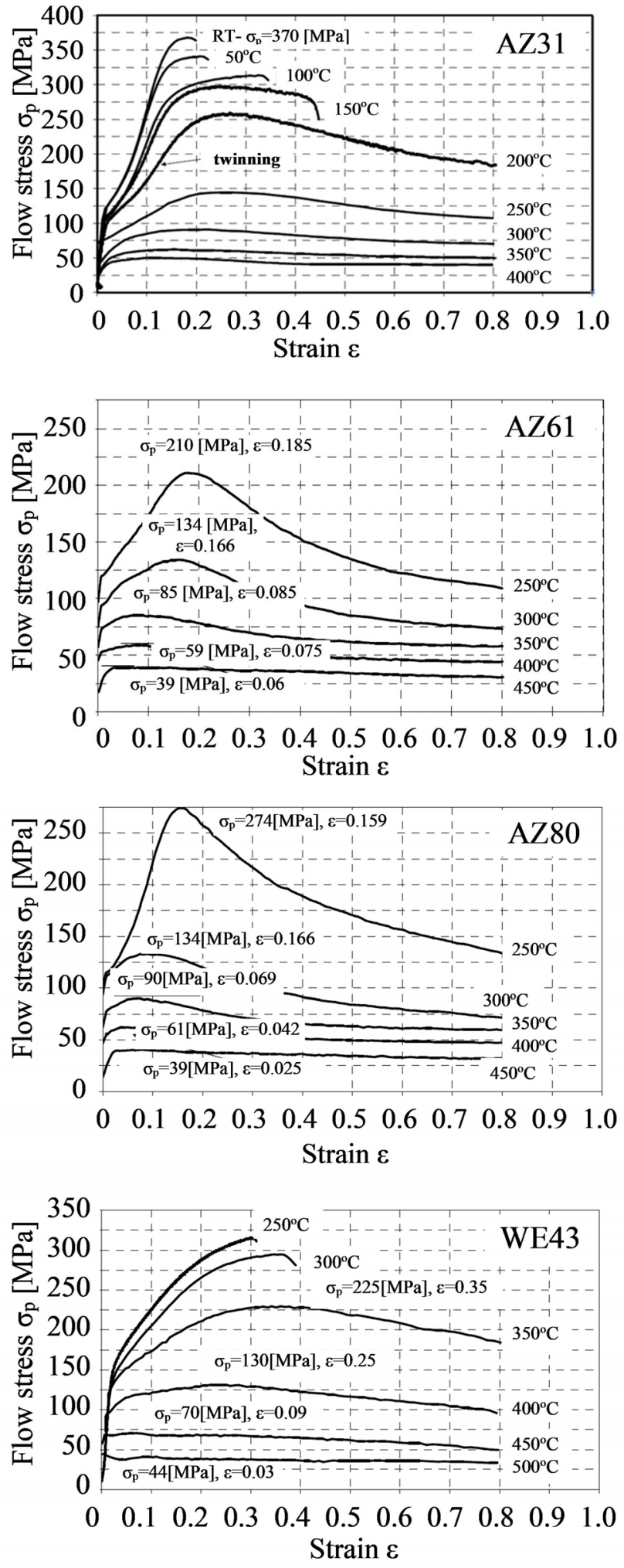

Fig. 2. Flow stress - strain relationships for magnesium alloys AZ31, AZ61, AZ80 and WE43

The tests were carried out on $1000 \mathrm{kN}$ hydraulic press and during the upsetting process the press ram displacement and the upsetting force were recorded. The specimens, after heating in a furnace to a suitable temperature, were carried to a special heating equipment mounted to the press platens, and then were upset. This equipment was designed in order to provide the uniform temperature distribution in the specimen during upset- ting. It consists of an electric heating system embedded in the punch and the die, both insulated from the press bases (Fig. 1). The upsetting of the specimens was realized to about one third of the initial specimen height or to the moment of a material cracking (Fig. 2). During upsetting any lubricants on specimen frontal surfaces were applied.

At temperature of $300^{\circ} \mathrm{C}$ for $\mathrm{Mg}-4 \% \mathrm{Li}$ alloy the maximum value of $\sigma_{\mathrm{p}}$ equals $90 \mathrm{MPa}$, and by $7.5 \% \mathrm{Li}$ it drops to value of $60 \mathrm{MPa}$ (Fig. 3). Flow stress-strain curves of alloy AZ31 are characteristic for alloy in which during deformation a mechanism of plastic strain called twinning occurs [10]. As it can be observed, the decrease of deformation temperature, below $250^{\circ} \mathrm{C}$ changes the shape of flow curve for tested alloys with $4.0 \%$ and $7,5 \%$ lithium. A curve is achieved which initially has concave shape, which is connected with intensive course of twinning in microstructure [11]. The presence of twinning mechanism in deformation of magnesium alloys decreases with the increase of lithium content and by big amounts of lithium $(7,5 \% \mathrm{Li})$ it is prac-
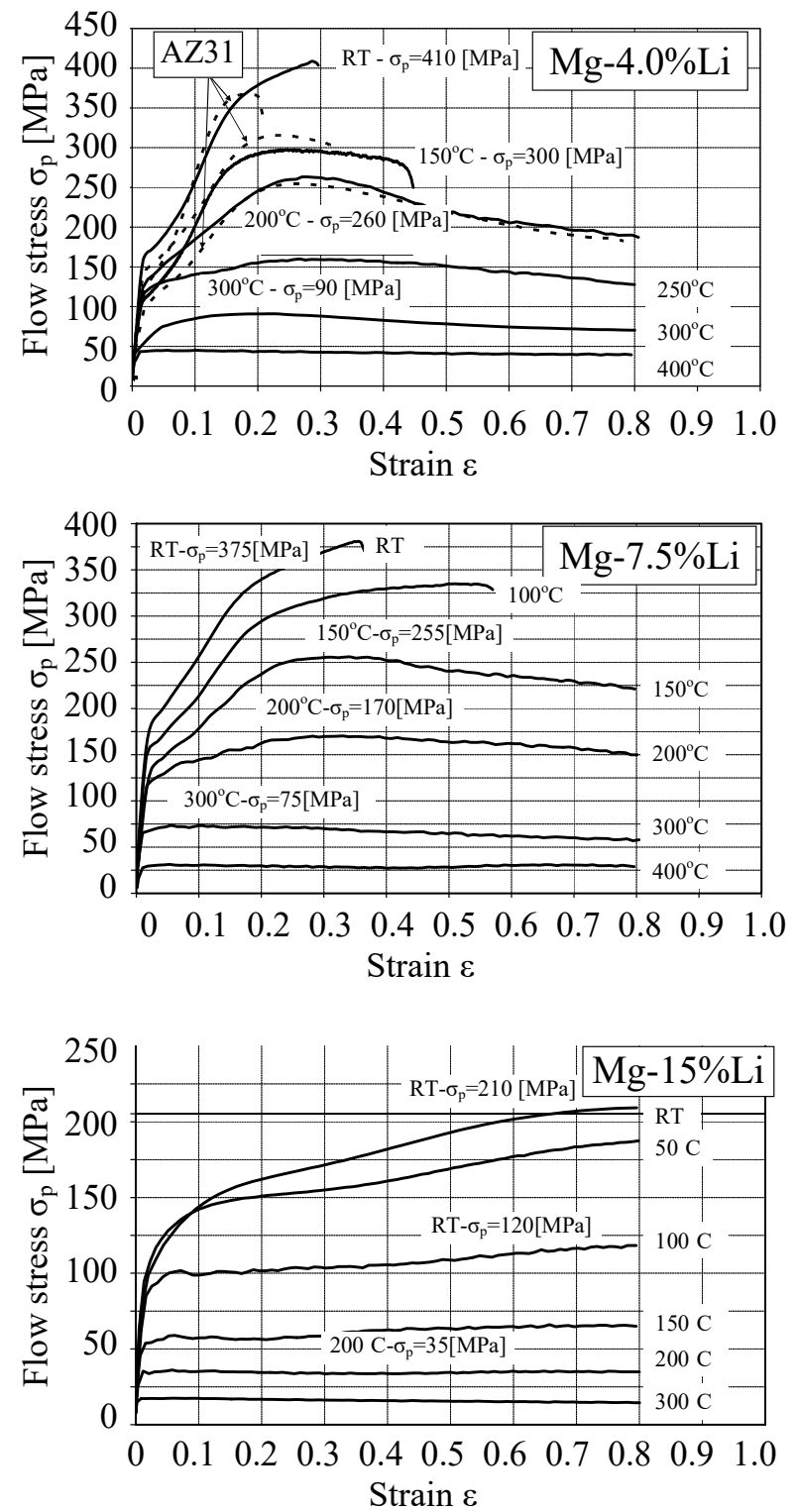

Fig. 3. Results of compression test of magnesium alloys $\mathrm{Mg}-4 \% \mathrm{Li}$, $\mathrm{Mg}-7,5 \% \mathrm{Li}$ and $\mathrm{Mg}-15 \% \mathrm{Li}$ 
tically observed from room temperature to $150^{\circ} \mathrm{C}$. It is visible in this range that the most beneficial susceptible to deformation is alloy $\mathrm{Mg}-15 \% \mathrm{Li}$. The alloy deformed in the temperature from room temperature to $300^{\circ} \mathrm{C}$ demonstrate the most advantageous susceptibility to plastic forming from investigated alloy.

Samples of magnesium alloy after deformation are often non-uniformly elongated in one direction, as a result of strong texture. As a result of modification of the initial content of $\mathrm{Mg}$ alloy which included $4 \% \mathrm{Li}$ by addition of $3.0 \% \mathrm{Al}$ the improvement of strength properties was achieved with only slight decrease of plasticity. Designing the technology of plastic processing of construction elements requires a precise determination of influence of process parameters on plasticity and microstructure of alloys. It has a significant meaning when designing products made of magnesium alloys which are to be used as construction elements for aviation industry and which are supposed to replace the currently used conventional products.

\subsection{Forging}

The main metalworking industrial production method is forging where the material is shaped by a multistage deformation. For magnesium a typical process is based on hot forging within a narrow scope of temperature. An example of multistage forging of aeroplane wheel hub and lever from the magnesium alloy AZ31 are shown in Fig. 4. A forging process was performed using a die forging hammer [11]. The forging stock included ingots with the diameter of $100 \mathrm{~mm}$ and length of $93 \mathrm{~mm}$ that were heated to the initial forging temperature equal to $350^{\circ} \mathrm{C}$ and $410^{\circ} \mathrm{C}$. The first stage included upsetting and initial forging, using 1-5 strokes (upsetting at the height of $70 \mathrm{~mm}$ ), then forging in a die impression (forging in 2-4 strokes was assumed). The executed tests show that the temperature of $350^{\circ} \mathrm{C}$ is too low to achieve a correct product in the conditions of hammer forging, so overlaps occurred. A correct forging was obtained for the alloy heated in the temperature of $410^{\circ} \mathrm{C}$. On the basis of results of compression tests an approximate function of flow stress which takes into account the temperature and the speeds of deformation, a numeric simulation of the forging process of a forging was conducted too.
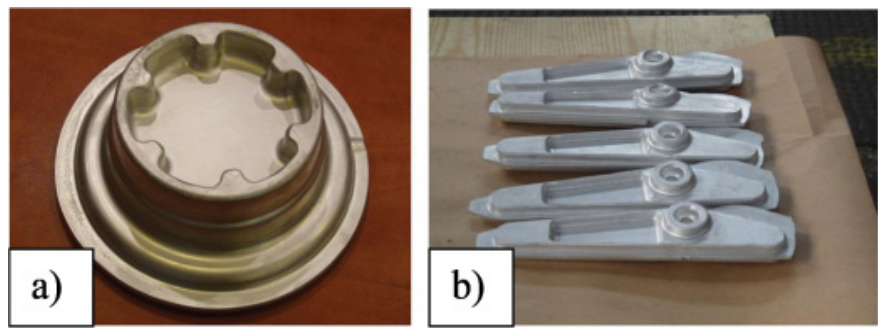

Fig. 4. View of forgings from AZ31 alloy and theirs models: a) semihub of wheel, b) lever after process at beginning temperature $410^{\circ} \mathrm{C}$

Rapid Prototyping (RP) techniques allow to make the prototypes of complex shapes, advanced structures, which include aircraft components [12]. An application of RP systems is particularly important in the manufacture of aircraft parts, for which it is difficult or even impossible to use traditional methods and tools. Prototype manufacturing by RP methods is associated with computer data preparation, process control and verification of models. Jetting Systems Prototypes (JSP) of the aircraft wheel hub and helicopter control system lever (Fig. 5) are the basis to conduct the model tests with an application of using photoelastic tests. The optically active coating placed on JSP hub and lever allowed to analyze the stresses distribution in the aircraft part based on the reflected light (Fig. 6). The obtained model results allow to develop the forging process of magnesium alloy aircraft parts and to improve the characteristics of forgings including geometrical and mechanical characteristics.
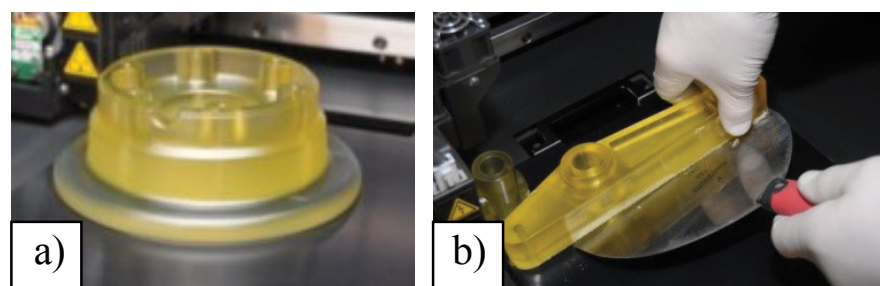

Fig. 5. Models of forgings: a) semi-hub of wheel, b) lever



Fig. 6. Stress distribution in the aircraft wheel hub - vertical force $4000 \mathrm{~N}$ to the hub (a), stress distribution in the aircraft wheel hub - vertical force $4000 \mathrm{~N}$ and $1500 \mathrm{~N}$ lateral force directed to the hub (b), stress distribution in the lever (c)

JSP model of the aircraft parts allows conduct the photoelastic tests with the application of the reflected light method using the model similarity between the real object model (of magnesium alloy) and the tested one (of photopolymer). Taking into account the model coefficient for the material the hub will be of plastically formed magnesium alloy, the occurring stresses are within the acceptable range.

These results (location and concentration of stresses) support the verification of the design parameters of the analyzed part, e.g. in the selection of quantity or arrangement of process openings, structural changes to reduce the weight of the product, etc. 


\subsection{Backward extrusion of profiles}

The extrusion process was carried out on the backward extrusion $5 \mathrm{MN}$ capacity hydraulic press type PH-LR 500 (Fig. 7).

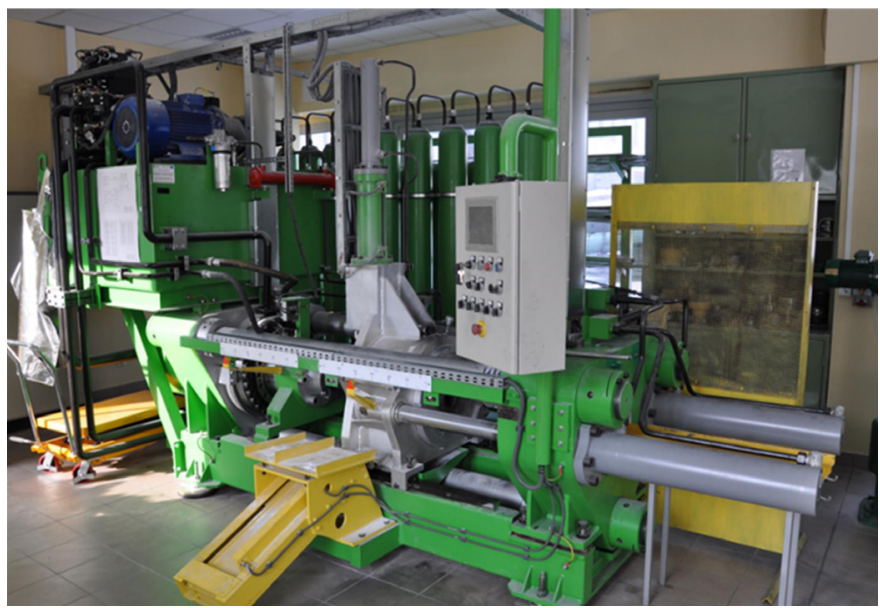

Fig. 7. Backward extrusion $5 \mathrm{MN}$ capacity hydraulic press - type PH-LR 500

This is three column press and it was designed and constructed to extrude mainly aluminum and magnesium alloys. The main operating sequence of the PH-LR 500 press is: - loading the billet into the container by the press loader, - billet upsetting, - extrusion, - shearing the extrusion butt, - die preparation, i.e. cleaning and lubricating, - moving the container to starting position. The press has two modes of the work: manual and automatic, and these both modes were applied in the tests. During extrusion several parameters of the process were recorded automatically (relative stem displacement, pressure in hydraulic system of the press, stem velocity and others). The backward extrusion processes were conducted at temperature $350^{\circ} \mathrm{C}$ and $400^{\circ} \mathrm{C}$ (i.e. temperature of the extrusion press container; temperature of the billet was the same or different than container temperature). The billets were heated to extrusion temperatures and maintained in a furnace for about 2 hours before extrusion. The diameters of billets for extrusion were $100 \mathrm{~mm}$ and $60 \mathrm{~mm}$, the length $250 \mathrm{~mm}$ and $180 \mathrm{~mm}$. The area of extruded sections matched area of circular sections diameters of $\phi 60, \phi 36$ and $\phi 20 \mathrm{~mm}$. Thus, the extrusion ratios $\lambda$ were equal $2.8,7.7$ and 25 for the billets of $100 \mathrm{~mm}$ diameter and 2.8 and 9 for the billets of $60 \mathrm{~mm}$ diameter, respectively.

Different shapes of cross-section of profiles for aviation application were obtained in the way of backward hot extrusion process. Some results of final products are presented in Fig. 8. It is possible to obtain profiles of complex shape with elements of varied wall thickness and with thin walls.

Microstructure of tested alloys in initial condition after extrusion is shown in Fig. 9. Before deformation the tested alloys AZ31 and AZ61 were characterised by single phase microstructure of solution $\alpha-\mathrm{Mg}$, whereas in microstructure of alloy AZ80 the presence of intermetallic phase $\gamma-\left(\mathrm{Mg}_{17} \mathrm{Al}_{12}\right)$ was found and which was confirmed by prior X-ray tests $[9,10,13,14]$.

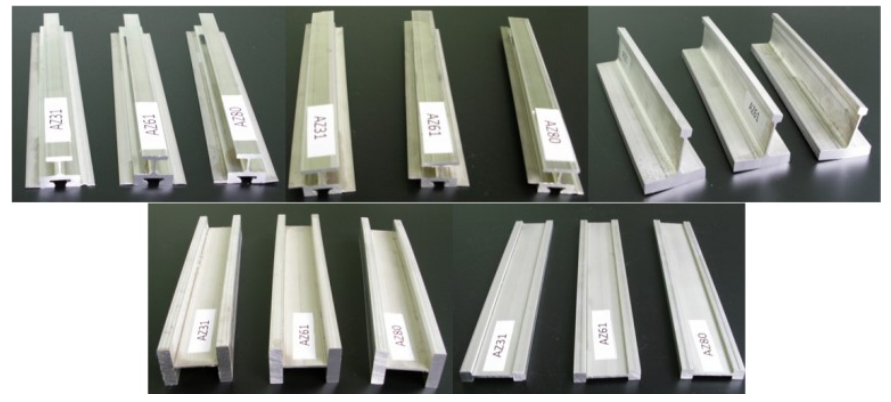

Fig. 8. Results of extrusion of profiles of complex shape with elements of varied wall thickness

The tested alloy WE43 was characterised with microstructure of $\alpha-\mathrm{Mg}$ solution. The presence of intermetallic phases $\mathrm{Mg}-\mathrm{Y}$, $\mathrm{Mg}-\mathrm{Nd}$ were also found in the microstructure of this alloy.

\section{KOBO extrusion}

As it was mentioned above, the main drawback of magnesium and its alloys is small deformability in room temperature. It is believed that magnesium alloys can be deformed in temperature above $200^{\circ} \mathrm{C}$. However, in result of recrystallization process it is difficult to maintain a fine grain structure of the alloys (Fig. 9). This difficulty may be avoided in an alternative low temperature extrusion technology, known as $\mathrm{KOBO}$ process $[15,16]$. Its main idea and options are shown in Fig. 10. The experimental 2,5 MN KOBO press used in the experiments is shown in Fig. 11.

The method combines the extrusion of the material with an additional plastic deformation caused by reversible torsion of die. Being induced this way super plastic mode of deformation makes possible to deform metals with very high deformation (SPD process) at low temperature (room temperature) $[17,18]$. Hence, despite of very low load capacity of the press the methods allows for the variety of metallic product to be extruded at room temperature from the billet, which size and dimensions are shown in Fig. 12 with value of extrusion ratio $\lambda$ up several hundreds.

Superplastic behavior of a metals under such deformation conditions is proven also in exact filling of a die opening, regardless how complicated it is and mode of extrusion - forward or sideway (Fig. 12). Very high extrusion ratio $\lambda$ (true deformation value $\varepsilon_{\mathrm{r}}$ of the order of 7) and low temperature of the process results in refinement of the grain structure and ensures high ductility of extrusion products. The pictures of the grain structure and tensile properties of the alloys extruded to the form of flats are shown in Fig. 13.

The comparison of these data with those of high temperatures backward extruded ones (structures in Fig. 9) may give an idea about the potential features of the methods. Among them, the possibility to control the final properties of the extruded alloys appear especially valuable. It comes from the number of $\mathrm{KOBO}$ process parameters, like amplitude and frequency of a die oscillations. Their optimal choice oriented toward the best exploiting properties of the extruded element will be also the subject of research enterprise. 


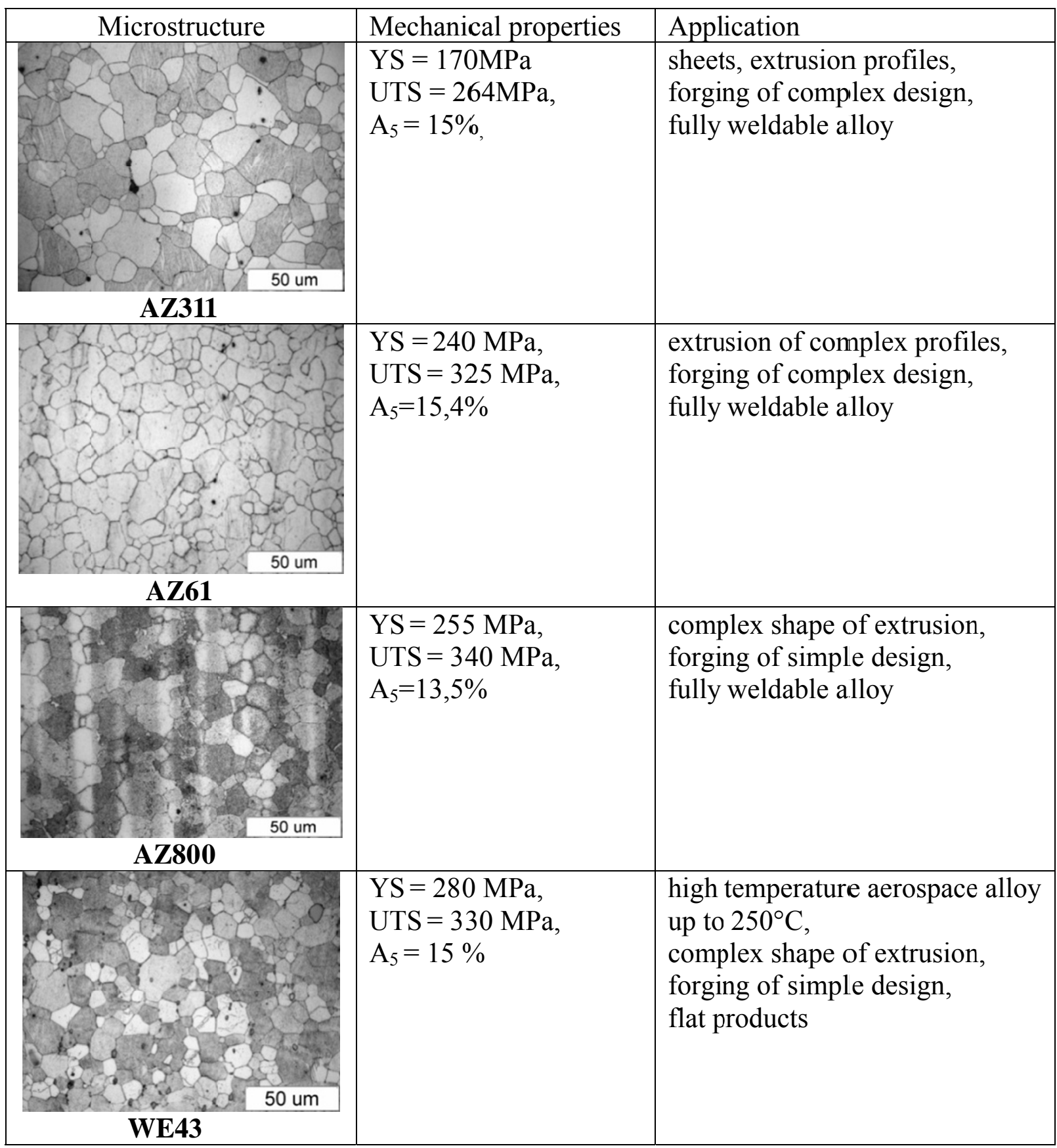

Fig. 9. Microstructure of investigated alloys after hot indirect extrusion using $5 \mathrm{MN}$ capacity hydraulic press - type PH-LR 500


Fig. 10. Diagram of KOBO concurrent extrusion (a) and sideways outflow of the material (b): 1 - punch, 2 - container, 3 - cyclically rotated matrix with slots on the side face, 4 - extruded material / charge, 5 - product 

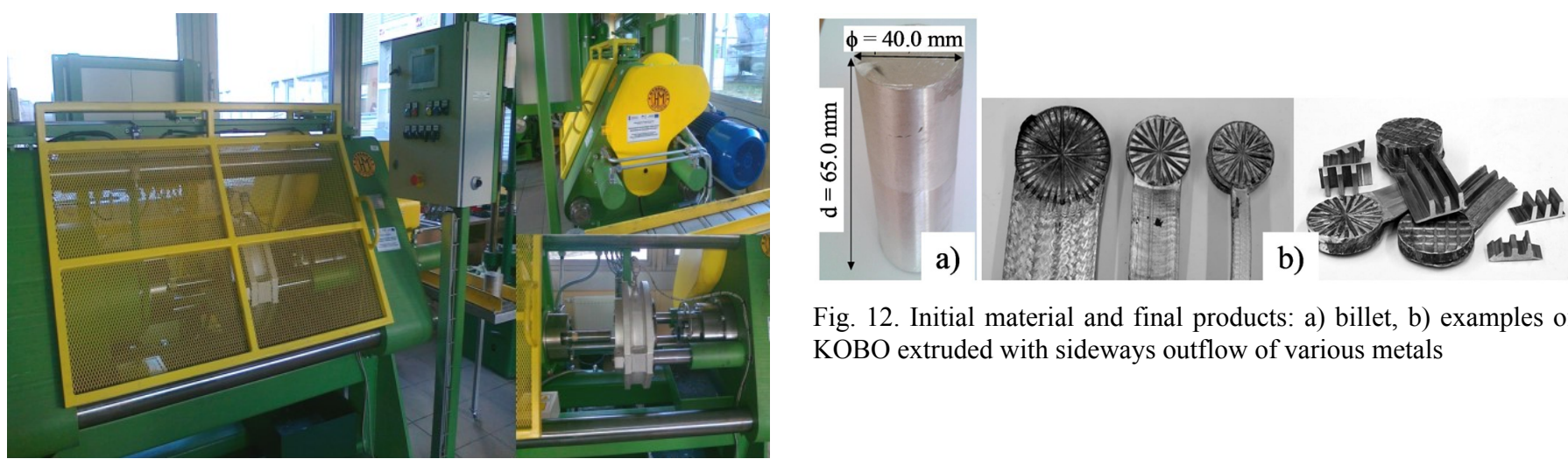

Fig. 12. Initial material and final products: a) billet, b) examples of KOBO extruded with sideways outflow of various metals

Fig. 11. Experimental KOBO press used in experiments

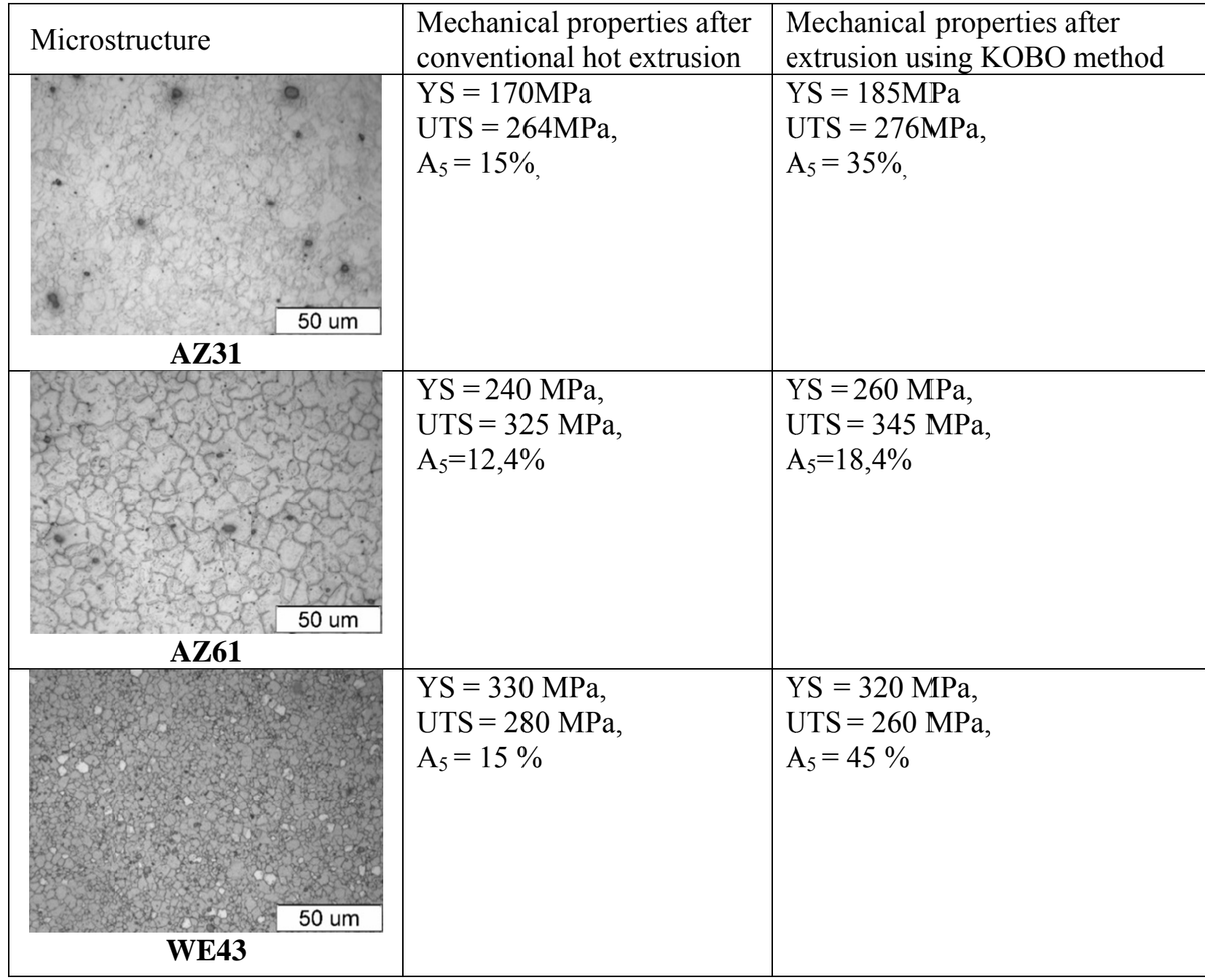

Fig. 13. Microstructure of investigated alloy after extrusion using KOBO method

\section{Conclusions}

Magnesium alloys can be processed by backward extrusion efficiently. The maximum speed at which magnesium alloys can be extruded is relatively slow and should be carefully balanced taking into account the extrusion process temperature and shape of a profile. To design the extrusion process for magnesium alloys, at the optimal speed and temperature, performing the upset- ting tests at elevated temperatures is very useful. Comparison of the relationships between: extrusion load, stem displacement and stem velocity and true strain - unit pressure relationship in upsetting test - for different magnesium alloys let to choose proper parameters for given material and conditions of the process to obtain required final product of special application. It was shown that different shapes of cross-section of profiles (complex shape with elements of varied wall thickness) for aviation application 
may be obtained in the way of backward hot extrusion process, but to determine proper parameters of extrusion process it is necessary to know exact information on initial features of given magnesium alloy - its macro and microstructure, mechanical properties and final results of transformation of the internal structure under conditions of plastic deformation.

Low temperature (below $200^{\circ} \mathrm{C}$ ) in $\mathrm{KOBO}$ extrusion technology of magnesium alloys, makes possibility to control the final properties of the extruded profiles and let to maintain a fine grain structure of the alloys. It comes from the number of KOBO process parameters, like amplitude and frequency of a die oscillations. It is possible to use the backward extrusion and $\mathrm{KOBO}$ processes for bulk metals and metallic chips.

It was obtained in the course of research work using magnesium alloys AZ31, AZ61, AZ80, WE 43 and Mg alloy with $\mathrm{Li}$ for production of thin - walled aircraft profiles. It has been shown the potential of the backward extrusion process of magnesium alloys and KOBO extrusion process to apply them for aeronautical applications. It was shown the possibility for indicating the best materials and parameters of the process to use e.g. bridge dies to produce different types of complex shape of cross sections which are the interest of aviation industry in light extruded products in order to save energy, costs etc. by reducing aircraft weight.

The rapid prototyping models allow to develop the forging process of magnesium alloy aircraft parts and to improve the characteristics of forgings including geometrical and mechanical characteristics.

\section{Acknowledgments}

financial support of Structural Funds in the Operational Program - Innovative Economy (IE OP) financed from the European Regional Development Fund - Project "Modern material technologies in aerospace industry", No POIG.0101.02-00-015/08 is gratefully acknowledged.

\section{REFERENCES}

[1] L. Choudhary, R.K. Singh Raman, Acta Biomater. 8, 916-923 (2012).

[2] G. Huang, R. Xin, X. Chen, F. Pan, T. Nonferr. Metal. Soc. 18, 170-174 (2008)

[3] K.F. Zhang, D.L. Yin, D.Z. Wu, Int. J. Mach. Tool. Manu. 46, 1276-1280 (2006).

[4] G. Sauer, Extrusion of Semifinished Products in Magnesium Alloys, in: M. Bauser, G. Sauer, K. Siegert, Extrusion, 2nd ed., ASM International, Materials Park, Ohio 2006.

[5] Y.Yang, B. Li, G.Z. Zhan, T. Nonferr. Metal. Soc. 18, 180-184 (2008).

[6] R.Ye. Lapovok, M.R. Barnett, C.H.J. Davies, J. Mater. Process. Tech. 146, 408-414 (2004).

[7] T. Balawender, Ł. Bieniasz, R.E. Śliwa, Hutnik - Wiadomości Hutnicze 8, 526-534 (2012).

[8] T. Balawender, R.E. Śliwa, Backward extrusion of magnesium alloy rods. International Scientific Conference PRO-TECH-MA, Bezmiechowa - Rzeszów, 2013

[9] I. Schindler, P. Kawulok, E. Hadasik, D. Kuc, J. Mater. Eng. Perform. 3, 890-897 (2013).

[10] D. Kuc, E. Hadasik, I. Schindler, P. Kawulok, R.E. Śliwa, Arch. Metall. Mater. 58 (1), 151-156 (2013).

[11] D. Kuc, E. Hadasik, J. Mizera et al., Solid State Phenomena 212, 11-14 (2014).

[12] R.E. Śliwa, G. Budzik, J. Bernaczek, T. Dziubek, The rapid prototyping of aircraft wheel hub model with use of techniques JS, SLA, FDM. Journal of KONES Power train and transport 18 (3), 439-443 (2011)

[13] T. Al-Samman, Acta Mater. 57, 2229-2242 (2009).

[14] T. Mikuszewski, Metalurgija 53 (4), 588-590 (2014)

[15] A. Korbel, W. Bochniak, Method of plastic forming of materials, U.S. Patent No 5,737,959 (1998), European Patent No 0711210 (2000).

[16] A. Korbel, W. Bochniak, P. Ostachowski, A. Paliborek, M. Lagoda, A .Brzostowicz, Int. J. Mater. Res. 107, 44-51 (2016).

[17] A. Korbel, W. Bochniak, P. Ostachowski, L. Blaz, Metall. Mater. Trans. A 42, 2881-2897 (2011).

[18] A. Korbel, W. Bochniak, Philos. Mag. 93, 1883-1913 (2013). 